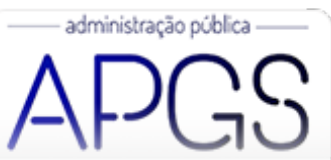

Administração Pública e Gestão Social ISSN: 2175-5787

apgs@ufv.br

Universidade Federal de Viçosa

Brasil

\title{
De Gata Borralheira à Cinderela: mas nem tudo é Conto de Fadas no Processo Sucessório de uma ONG
}

Sousa Cecílio \{in memoriam\}, Larissa; Godói-de-Sousa, Edileusa; Moro Bueno Mendonça, Juliana De Gata Borralheira à Cinderela: mas nem tudo é Conto de Fadas no Processo Sucessório de uma ONG Administração Pública e Gestão Social, vol. 12, núm. 2, 2020

Universidade Federal de Viçosa, Brasil

Disponible en: http://www.redalyc. org/articulo.oa?id=351562414009

Esta obra está bajo una Licencia Creative Commons Atribución-NoComercial-SinDerivar 3.0 Internacional. 


\title{
De Gata Borralheira à Cinderela: mas nem tudo é Conto de Fadas no Processo Sucessório de uma ONG
}

\author{
From no-one to Cinderella: It's not all fairy tale in the succession process of a non governmental organization \\ De cenicienta a princesa: Ni todo es cuento de hadas em el proceso de sucesión de uma organización no \\ gubernamental
}

Larissa Sousa Cecilio \{in memoriam\}

Universidade Federal de Uberlândia, Brasil

Redalyc: http://www.redalyc.org/articulo.oa?

Edileusa Godói-de-Sousa

Universidade Federal de Uberlândia, Brasil

edileusagodoi@ufu.br

Juliana Moro Bueno Mendonça

Universidade Federal de Uberlândia, Brasil

juliana_mbueno@hotmail.com

\section{Resumo:}

A senhora Maria de Lourdes teme o futuro. Seu antigo cargo nunca significou nada, mas agora a Associação dos Artesãos de Uberlândia está em suas mãos. Ela não queria assumir as responsabilidades, mas não abandonaria a associação. Nenhum associado pensava sobre os impactos do processo sucessório, nunca ouviram sobre a necessidade de planejar esse processo ou sobre as habilidades para lidar com crises na sucessão. A análise do caso objetiva discutir a importância do planejamento da sucessão nas organizações, focando nos empreendimentos sociais, conscientizar sobre a importância de se agir de maneira ética e transparente e instigar debate sobre o dilema do caso.

Palavras-Chave: Processo Sucessório, Organização do Terceiro Setor, Dilema Ético.

\section{Aвstract:}

Maria de Lourdes fears the future. Her last position never meant anything, but now the Association of Artisans in Uberlândia, Brazil, is in her hands. She didn't want to take responsibility, but she never would abandon the Association. None of the associates thought about the impacts of the succession process, and they never heard about the need to plan this process, or the skills to deal with succession crises. The purpose of this case analysis is to discuss the importance of succession planning in organizations, focusing on social enterprises, raising awareness of the importance of acting ethically and transparently, and instigating debate of about the dilemma of the case.

KEYwORDS: Succession Process, Organization of the Third Sector, Ethical Dilemma.

\section{RESUMEN:}

La señora María de Lourdes teme el futuro. Su antiguo cargo nunca significó nada, pero ahora la Asociación de los artesanos de Uberlândia está en sus manos. No quería asumir las responsabilidades, pero no abandonaría la asociación. Ningún asociado pensaba sobre los impactos del proceso sucesorio, nunca oyeron sobre la necesidad de planificar ese proceso o sobre habilidades para lidiar con crisis en la sucesión. El análisis del caso objetivo desea discutir la importancia de la planificación de la sucesión en las organizaciones, enfocándose en los emprendimientos sociales, concientizar sobre la importancia de actuar de manera ética y transparente y instigar el debate sobre el dilema del caso.

Palabras Clave: Proceso Sucesor, Organización del Tercer Sector, Dilema Ético. 


\section{INTRODUÇÃO}

Janeiro de 2012. Como já era previsto, devido à formação de chapa única às vésperas da sucessão, o senhor Henrique toma posse como novo presidente da Associação dos Artesãos do Triângulo Mineiro (ASSARTRIM). Na gestão anterior, presidida pelo senhor João Alexandre, Henrique atuou como tesoureiro e agora os papeis se inverteram: Henrique é presidente e João Alexandre, tesoureiro. Os associados estavam acostumados com a estrutura da diretoria da ASSARTRIM, João Alexandre permanecia sempre no poder e representava o "pai" da associação. Ele exerceu o papel de presidente durante oito mandatos consecutivos, o que representa dezesseis anos nessa função.

Senhor João: "Henrique, muito boa nossa estratégia para sucessão, como tesoureiro vou poder gerir os recursos financeiros, como venho fazendo, pois eu domino essa parte, e continuar cuidando da associação, fique tranquilo, tudo vai dar certo! Devido ao novo estatuto de 2010, a cada dois anos temos que fazer eleições, então a partir desse ano (2012) você assume a presidência, quanto aos outros cargos, o que acha?”

Senhor Henrique: "Então, faz como você tinha me dito semana passada, diz que a pessoa não precisa fazer nada, que é só burocracia para o cargo não ficar vazio, mas que a gente toma conta"

Senhor João: "Combinado"

No mandato de 2012, a senhora Maria de Lourdes foi convidada para assumir o cargo de Vice-Presidente, mas estava sossegada, pois sabia que "não precisava fazer nada", seu cargo era "apenas no papel”. Com isso em mente, ela aceitou o convite e foi eleita.

Senhora Maria de Lourdes: "Senhores João e Henrique, como sabem eu sempre fui dona de casa e faço meus produtos artesanais pois é um hobby que adoro, sou associada para dar força a nossa instituição e porque gosto muito da companhia dos colegas. Não entendo de muita coisa, mas como me tranquilizaram, eu aceito ser vice"

Entretanto, em junho de 2013, um fato completamente inesperado aconteceu. Devido a diversas pressões que o Henrique sofreu no cargo de presidente e ao seu despreparo para lidar com as circunstâncias adversas, ele abandonou a associação e mudou-se de cidade. E agora, Maria? Como manter a Associação dos Artesãos de Uberlândia?

\section{2. "Passando o Bastão": um PRocesso sucessório traumático}

A Associação dos Artesãos de Uberlândia foi fundada em 02 de julho de 1979, no município de Uberlândia (MG), e conta atualmente com aproximadamente oitenta artesãos associados. A rotina de trabalho é a seguinte: Cada artesão confecciona seus produtos de forma independente e todos os domingos os associados se reúnem em feiras na praça para expor e vender seus produtos, bem como recolher encomendas junto aos clientes. Os produtos oferecidos pela ASSARTUDI são aplicações em tecido; arranjos florais desidratados e em seda; artesanatos em bambu; bijuterias; biscuits; bolsas; bordados à mão e máquina; brinquedos; cerâmica; cordões; artigos em couro e, crochê; embalagens para presentes; enxovais infantis; materiais em resina epóxi; jogos de banheiro, cozinha e quarto; luminárias; artigos em madeira; artesanatos com miçangas; móveis rústicos; panos de prato; pedrarias; pinturas em tecido e tala; bordados em ponto cruz; jóias de prata; roupas cearenses, hippies e indianas; sabonetes artesanais pintados; sais para banho; tatuagens temporárias; toalhas bordadas e pintadas; tapetes; tecelagem em geral; tricô; vasos ornamentais; velas decoradas e vidros jateados e pintados. A associação também oferece bebidas, comidas típicas, doces caseiros, plantas medicinais, quitandas e sucos naturais. A associação não possui uma sede ou um ponto de vendas fixo.

O serviço de montagem e desmontagem das barracas é terceirizado e pago por cada associado por intermédio de uma taxa mensal. Devido ao fato de a associação não ter parceiros e não contar com subvenções, a origem dos recursos se limita às taxas cobradas de cada artesão. As feiras promovidas pela associação são abertas a todo o público e conjuntos musicais são convidados para tocarem durante sua realização. 
Para se tornar um associado é necessário pagar uma taxa de entrada (compra da barraca que será utilizada na feira pelo artesão) e uma mensalidade. Os encontros entre os associados acontecem nas feiras e em reuniões ordinárias que são realizadas a cada três meses, promovidas pela diretoria.

A diretoria é composta por presidente, vice-presidente, primeiro secretário, segundo secretário, tesoureiro e gestor de relações públicas.

As funções da diretoria, conforme o estatuto da ASSARTRIM, são: Executar a programação anual das atividades; elaborar e submeter à Assembleia Geral a proposta de programação anual; elaborar e apresentar à Assembleia Geral o relatório anual; decidir sobre medidas administrativas; designar, entre seus membros, substitutos para diretores, em caso de impedimento temporário; autorizar operações financeiras; providenciar execução de quaisquer obras, reparos ou consertos imprescindíveis às atividades normais da Associação; elaborar balancetes financeiros mensais e balanço anual; reunir-se com instituições públicas e privadas para mútua colaboração em atividades de interesse comum.

Apesar dessas funções previstas no estatuto serem atribuídas a toda a diretoria, elas eram concentradas apenas no cargo do presidente. Além disso, a Assembleia Geral (formada pelos associados efetivos) quase não se reunia e o senhor João Alexandre comunicava as decisões tomadas a cada associado de forma individual durante as feiras. Ou seja, não integrava as informações e as mostrava de modo transparente.

João Alexandre sabia da importância que os associados atribuíam às feiras, desta forma, durante seus oito mandatos, ele se esforçou para mantê-las e melhorá-las. Todos os artesãos concordavam, pelo menos aparentemente, que a função primordial da liderança era a manutenção das feiras para exposição dos artesanatos e, como o presidente conseguia esse resultado, ninguém questionava sua gestão.

Quando Henrique assumiu o cargo de Presidente em 2012, ele ficou frente a frente com as dificuldades pelas quais a ASSARTRIM estava passando, mas que ninguém tinha conhecimento porque elas eram "varridas para debaixo do tapete" por João Alexandre. Diante do medo de ser responsabilizado pela falta de gestão profissional na organização e do receio de o grupo descobrir ações encobertas em sua gestão (havia um processo jurídico contra a associação de $\mathrm{R} \$ 138.000,00$ gerado por um dos encarregados terceirizados da montagem e desmontagem das barracas. Esse processo teve início na gestão de João Alexandre, mas não foi comunicado pelo antigo presidente), Henrique sentiu-se pressionado demais e tomou a decisão repentina, inesperada e imediata de abandonar o cargo e desfiliou-se da associação. Não houve nenhum aviso prévio.

Dessa forma, no dia 02 de junho de 2013, Maria de Lourdes, que até então era vice-presidente, assume o cargo de presidente. Isso foi para ela um baque muito grande, porque ao assumir seu antigo cargo, sua função estava "apenas no papel”, ela jamais pensou que assumiria a presidência e nem mesmo queria isso, mas como está previsto no estatuto da associação, "compete ao vice-presidente substituir o presidente nos impedimentos eventuais", foi compelida a tomar posse. Assim, Maria de Lourdes, de um dia para o outro, percebeu que a responsabilidade era toda sua a partir de agora, ela assumia o cargo de presidente da ASSARTRIM, até o próximo processo sucessório previsto para o início de 2014.

Os personagens do caso podem ser descritos, resumidamente, da seguinte maneira:

- João Alexandre: Representa a figura do fundador e ocupou o cargo de presidente durante oito mandatos (16 anos). É considerado um líder autocrático, o "pai" da Associação. Ele sempre realizou todas as funções sem o auxílio da diretoria e dos demais associados. Ocupa atualmente o cargo de tesoureiro, mas tem interesse em retornar ao cargo de presidente;

- Henrique: Ocupou o cargo de tesoureiro durante a última gestão do senhor João Alexandre. Ele chegou a iniciar algumas mudanças na gestão do empreendimento, isto é, adotou uma política mais democrática. Contudo, devido às pressões excessivas, abandonou o cargo e a Associação, destinando todas as incumbências à vice-presidente.

- Maria de Lourdes: Ocupou o cargo de vice-presidente durante a gestão do senhor Henrique e, quando o mesmo saiu de maneira repentina, ela recebeu o cargo de presidente. Possui ideias novas para a Associação e tem exercido uma liderança democrática. Tem ainda uma visão mais voltada para a 
dimensão social da Associação e busca desmistificar a figura paternalista de João Alexandre como pilastra da Associação.

Se nas gestões de João Alexandre e Henrique os associados permaneceram alienados quanto aos processos e à mercê das decisões tomadas pelo Presidente, Maria de Lourdes passa a tomar atitudes para envolver toda a Associação nos processos administrativos. Algumas das mudanças que ela deseja implementar junto a todos os associados são: Reestruturação de feira, retirada de produtos industrializados no comércio da associação, fidelidade dos processos organizacionais ao estatuto da Associação e maior tolerância no que se refere ao pagamento e prazos das mensalidades. Além disso, ela busca reunir esforços de toda a Associação para a formação de parcerias com instituições públicas e privadas, bem como com outras associações. Entretanto, essas novidades causavam insegurança no Sr. João Alexandre, pois este temia perder seu lugar central na Organização: "Passar o bastão" nunca pareceu ser uma tarefa tão árdua.

A nova presidente estava diante de um desafio, pois não foi preparada para assumir o cargo, ademais, enfrentava a resistência de Alexandre, que por se sentir "pai" da associação não queria que nenhuma pessoa obtivesse sucesso na direção. Razão e emoção se misturam e sentimentos de medo, ciúme e inveja parecem querer justificar uma postura egoísta de reinar a qualquer custo. Alexandre sente-se acuado, afinal, ele fez e desfez ao longo de muitos anos, "maquiando" seus erros.

\section{Os Impactos da Crise}

Os membros da ASSARTRIM sempre afirmaram viver princípios e valores de união, auxílio ao próximo, originalidade, criatividade, responsabilidade, compromisso, persistência. Entretanto, todos sabiam que não funcionava bem assim. Os recém-associados quase não tinham voz junto ao presidente, a maioria dos membros não estava satisfeita com a gestão, pois afirmavam que havia monopólio de poder e os stakeholders (clientes, fornecedores e representantes da comunidade) não conheciam a diretoria e nem mesmo tinham interesse em participar das decisões da ASSARTRIM.

A Associação queria ser reconhecida na cidade e região, mas não se preocupava em desenvolver relacionamentos com a comunidade; o presidente estava ocupado demais resolvendo questões para melhoramento da estrutura das feiras e, como não delegava funções, os esforços para fidelização de clientes e para desenvolvimento de parcerias eram praticamente inexistentes.

Com a crise do processo sucessório, os artesãos assumem uma postura estática, isto é, ninguém manifesta opiniões e toma atitudes que fogem da rotina. Maria de Lourdes interpreta essa postura como medo e assombro diante das circunstâncias. Medo de que a nova presidente também resolva abandonar a associação, levando-a a fechar suas portas e assombro porque nenhum associado jamais poderia prever uma crise tão séria como essa e, desta forma, ninguém sabia como reagir. A reputação da ASSARTRIM junto aos stakeholders também está em jogo, o que eles iriam pensar quando percebessem a crise?

Além de estar diante de todos esses desafios, Maria de Lourdes ainda tinha que lidar com a resistência de João Alexandre, que não queria que nenhuma mudança drástica acontecesse para que sua posição de poder não sofresse dano. Por ter sido líder de longo prazo, ele desfrutou de privilégios e exerceu grande influência na ASSARTRIM, assim, ele teme que essa estima seja perdida quando for sucedido.

\section{Um vestígio de luz}

O empreendedorismo social é visto como um processo que tem início com uma ideia que está associada a um ou mais problemas sociais relevantes. A sua força e criatividade estão no seu esperado "impacto social", ou seja, na sua capacidade de gerar soluções eficientes e eficazes para os problemas identificados. Além disso, esses empreendimentos devem ter a capacidade de conduzir as pessoas e a gestão dos fatores produtivos e materiais, com vistas à realização das suas metas. Principalmente respeitando as características, explorando as virtudes da comunidade de trabalho e potencializando as forças geradas pela união dos membros. Em outros termos, significa valer-se do fato de que um elemento comunitário, de ação e gestão conjunta, cooperativa e solidária, apresente no interior dessas unidades econômicas efeitos tangíveis e concretos sobre o resultado da operação econômica (Melo Neto \& Froes, 2002). 
No que se refere ao processo sucessório, ele implica em uma série de variáveis e determina mudanças na vida das pessoas que assumirão a organização, assim como no futuro do empreendimento e na complexa teia de interações entre seus membros. Ainda que o processo seja relevante para a própria sobrevivência da organização, poucas incluem no conjunto de suas estratégias os planos de sucessão, o que ocasiona diversos problemas na gestão que, na maioria das vezes, poderiam ser antecipadamente resolvidos. Isso acontece, em parte, porque os fundadores têm o sentimento de serem eternos, não sendo premidos pela mudança. O processo de sucessão pode ser um momento de vulnerabilidade para a organização ou pode ser uma oportunidade de diversificar as lideranças e de avanços significativos em termos de desenvolvimento, tanto para a organização como para os envolvidos no processo. Este momento tão delicado e perigoso muitas vezes se perde entre as expectativas e necessidades dos membros organizacionais, que são entre si, bastante diferentes. Neste sentido, a sucessão demanda análise de relações entre vários agentes, tais como fundador, sucessores, fornecedores, clientes, funcionários e demais stakeholders envolvidos (Godói-De-Sousa, 2010).

Dependendo do tempo de iniciação, da amplitude e do ritmo de mudança das pessoas e da organização, é necessário seguir um padrão de desenvolvimento de regras a serem implementadas. Contudo, não existe uma fórmula mágica que impeça os conflitos e as incertezas desencadeados durante um processo sucessório e nem existem modelos de processos sucessórios idênticos, para cada caso é desenvolvido um plano que contempla diversos fatores, ou seja, cada organização tem de descobrir as suas próprias soluçóes e estas têm de ser construídas na medida da própria identidade do empreendimento social (Godói-De-Sousa, 2010).

Apesar de seu sentimento de impotência e despreparo para lidar com as circunstâncias decorrentes do processo sucessório, Maria de Lourdes não admite a ideia de abandonar a ASSARTRIM assim como fez Henrique. Ela vê potencial na associação para superar as adversidades e crescer com a crise. Além disso, os associados afirmaram não medir esforços para ajudar a nova presidente e ela sabe que se as experiências de cada associado se somam, é de se esperar que propiciem maior acerto nas decisões. Um novo período se inicia para a Associação dos Artesãos de Uberlândia, balizado pela busca por uma gestão transparente, ética e cooperativa.

\section{Notas de Ensino}

\subsection{Objetivos Educacionais}

O presente caso de ensino tem como objetivo educacional discutir a importância do processo sucessório nas organizações, dando destaque às particularidades no terceiro setor. Sabe-se que a gestão do processo de sucessão em organizações do terceiro setor é uma recente área de investigação inserida na Teoria das Organizações e da Administração, tanto no Brasil quanto nos estudos internacionais. O processo sucessório passou a ser motivo de interesse para esses empreendimentos devido ao fato de que o terceiro setor tem iniciado o que pode ser denominado "era de transição", com a sucessão da maior parte das lideranças que hoje atuam no setor (Godói-de-Sousa, 2010). A partir do início do século XXI, a literatura internacional tem desenvolvido diversos trabalhos no que diz respeito ao processo sucessório em organizações do terceiro setor (Adams, 2005; Brinckerhoff, 2007; Banavoglia \& Mackinnon, 2011; Goler, 2003; Hall, 2006; Kunreuther, 2005; Liteman, 2003; Nobles, 2006; Teegarden, 2004; Williams, 2005). No Brasil, ainda existem poucos estudos a respeito do tema de sucessão em organizações do terceiro setor. Uma das explicações para isso está na dificuldade de acesso a esse tipo de organização no país, seja pela existência de poucos dados sistemáticos registrados em banco de dados oficiais ou pela própria resistência das lideranças dessas organizações em participarem de pesquisas sobre o tema de sucessão. Talvez isso se dê porque alguns ainda não têm maturidade suficiente para lidar abertamente com esse tema (Godói-de-Sousa, 2010).

Um dos poucos estudos de que se tem conhecimento no Brasil foi realizado por Comini e Fischer (2009) com o intuito de compreender o nível de consciência e as dificuldades dessas organizações sobre a questão da 
sucessão. A partir dos resultados, as autoras concluíram que, embora esses gestores estejam preocupados com o processo de sucessão, pouco se tem realizado em termos de estruturação e planejamento desse processo.

O caso tem mais dois objetivos importantes. O primeiro é conscientizar o aluno de que o sucesso sólido na carreira não é alcançado "pisando" nos outros. É necessário, portanto, mostrar ao futuro gestor a importância de investir na formação de profissionais éticos. O segundo é instigar o debate a respeito do dilema do caso que se manifesta na seguinte questão: Como preparar a organização para o futuro, por intermédio de práticas éticas e transparentes, abarcando, sobretudo, a necessidade de preparar lideranças futuras para um processo sucessório adequado?

\subsection{Utilização Recomendada}

O caso pode ser adotado como parte da didática de ensino em cursos de graduação e pós-graduação em Administração e Ciências Contábeis, notadamente em disciplinas ligadas a gestão de pessoas, ética e planejamento. $\mathrm{O}$ caso ainda pode ser utilizado em cursos de extensão voltados para os gestores sociais. Temáticas imbricadas à discussão do caso podem ser detalhadas e retomadas, como, por exemplo, poder, processo sucessório, empreendedorismo social e tipologias de liderança.

\subsection{Questóes para Discussão do Caso}

1. Comente criticamente o processo sucessório ilustrado no caso. Em seguida explique para Maria de Lourdes, que está pensando no futuro da organização, quais são as prerrogativas para um processo sucessório profissional e eficaz.

2. Em sua opinião, quais as consequências para a organização como um todo quando seu dirigente não age de maneira ética e transparente? Para esta reflexão, retome a história do caso.

3. Caracterize as tipologias de liderança dos personagens do caso e avalie potenciais prós e contras em relação a cada escolha.

4. À luz do caso exposto, qual a importância de envolver o grupo (associados) no planejamento da organização?

\subsection{Dinâmicas para Discussão e Análise do Caso}

Recomenda-se trabalhar as questóes utilizando a dinâmica de júri simulado. Como o nome diz, é a simulação de um tribunal, em que os participantes têm funções predeterminadas. Os objetivos da dinâmica são estudar e debater um tema, levando todos os participantes do grupo a se envolver e tomar uma posição, exercitar a expressão e o raciocínio e desenvolver o senso crítico.

A proposta é a formação de três grupos: Dois grupos de debatedores (com o mesmo número de pessoas) e uma equipe responsável pelo veredicto (o júri popular, com um número menor de componentes). O papel do professor é o de coordenar a prática, delimitando o tempo para cada grupo defender sua tese e confrontar a tese defendida pelo grupo oponente. Cabe, portanto, ao professor expor uma questão por vez, assim será possível analisar as convergências e divergências dos apontamentos dos debatedores (papel do júri popular), no intuito de desenvolver um olhar mais amplo na análise de cada pergunta.

É importante dar um tempo inicial para os alunos socializem suas informações no grupo, antes do início do debate. A partir daí cada grupo lança a sua tese inicial, defendendo seu ponto de vista na medida em que surjam réplicas e tréplicas. O professor, como coordenador da atividade, também pode lançar perguntas que motivem o debate, evitando fornecer respostas ou apoiar alguma das posições. 
Por fim, cada grupo tem um tempo para suas considerações finais. $\mathrm{O}$ júri popular, então, se reúne para socializar suas anotações, feitas ao longo da atividade, e decretar o veredicto. Nesse momento de encerramento, cabe ao professor ofertar um feedback aos participantes, complementando as análises quando for o caso.

\subsection{Possíveis Alternativas de Resolução}

\section{- Análise da primeira questão:}

Conforme Gonçalves (2002), a sucessão implica em uma série de variáveis e determina mudanças na vida das pessoas que assumirão a organização, assim como no futuro do empreendimento e na complexa teia de interações entre seus membros. Dependendo então do tempo de iniciação, da amplitude e do ritmo de mudança das pessoas e da organização, é necessário seguir um padrão de desenvolvimento de regras a serem implementadas. No entanto, não existem modelos de processos sucessórios idênticos, para cada caso é desenvolvido um plano que contempla fatores individuais (Velloso, 2012).

A sucessão conduzida como um processo permite que, no decorrer do movimento, a(s) pessoa(s) que mais se encaixe $(\mathrm{m})$ na necessidade do empreendimento seja $(\mathrm{m}) \mathrm{a}(\mathrm{s})$ que realmente venha $(\mathrm{m})$ a gerir o mesmo, de forma a perpetuá-lo (Gonçalves, 2002).

Pouco se encontra na literatura sobre o preparo dos sucessores ao poder. Segundo Velloso (2012), organizações americanas contam com o apoio de muitos especialistas para fazer a transição com sucesso. No Brasil, os empreendedores não têm o mesmo cuidado ou o mesmo interesse em planejar o processo de sucessão.

Devido à escassez de estudos sobre o tema "sucessão em empreendimentos sociais", Godói-de-Sousa (2010), por exemplo, utilizou-se dos estudos de Lumpkin e Dess (1996), os quais demonstram que as iniciativas de criação das organizações empreendedoras são o resultado da combinação de três perspectivas: A do indivíduo, que decide empreendê-lo; a da organização, em termos de estrutura, estratégia e cultura adotadas para conformá-lo; e a do ambiente em que o empreendimento está inserido, com quem interage e cujas características influenciam em seu desempenho. Assim, a partir desses estudos, é possível a proposta de análise da sucessão como um processo que envolve também três dimensões: Indivíduo, organização e ambiente.

A dimensão indivíduoabrange a relação entre sucedido e sucessor dentro da organização. Desse modo, o individuo que exerce papel de sucedido pode ser representado tanto por um grupo de pessoas que criou o empreendimento como por aquele empreendedor social cuja figura se destaca entre a liderança vigente. Já o indivíduosucessor corresponde à pessoa - ou grupo de pessoas - que substitui a posição previamente ocupada pelo(s) antecessor(es), não existindo a necessidade de os sucedidos terem falecido, mas somente deixado de ocupar a posição (Godói-de-Sousa, 2010).

De acordo com Adams (2005), é comum que as identidades do fundador e do empreendimento social tornem-se entrelaçadas e, muitas vezes inseparáveis. A organização e o nome do fundador passam a ser inseparáveis na mente dos stakeholders, apesar de também conhecerem outros associados, devido à importância que esses stakeholders atribuem aos gestores organizacionais. Desta forma, o desafio após a sucessão será o restabelecimento da identidade do fundador como algo separado da identidade do empreendimento. Para a organização, o desafio será convencer tanto o público interno quanto o externo de que a organização pode existir e se sustentar sem a figura do fundador.

$\mathrm{Na}$ dimensão organização, por sua vez, considera-se o perfil da organização - origens, missão, valores, produtos e serviços, rotinas -, a forma organizacional - natureza do trabalho, estrutura, momentos críticos, aprendizados - e a governança organizacional - processo decisório, controle e avaliação, planejamento e comunicação. $\mathrm{Na}$ ótica de Matias-Pereira (2010), governança diz respeito aos processos de administração e controle das organizações. Ademais, refere-se à possibilidade de se construir uma gestão mais profissional 
e transparente, diminuir a assimetria informacional, atenuar o problema de agência, convergir os interesses de todas as partes relacionadas e maximizar a criação de valor na organização (Leal \& Famá, 2007). Neste sentido, é importante, nas orientações para Maria de Lourdes, romper com uma visão restritiva pautada apenas da dimensão do indivíduo e considerar que essa primeira dimensão está inserida na segunda, que por sua vez está imersa na terceira (cabe ao professor nessa questão retomar o primeiro objetivo do caso).

A última dimensão, o ambiente, abrange os seguintes elementos: Leis, fornecedores, parceiros, fatores políticos, lideranças locais, clientela, comunidade, entre outros stakeholders. Visto desta forma, a teoria dos stakeholders constitui também uma importante referência para a condução de um processo sucessório, uma vez que permite verificar a influência de cada um dos grupos envolvidos com o empreendimento - os associados, clientes, comunidade, fornecedores, governo, empregados, entre outros - e entender como essa influência acontece (Godói-de-Sousa, 2010).

Ao identificar a rede de influência de cada stakeholder é possível a minimização de riscos durante um processo de sucessão, que pode também ser facilitado quando o empreendimento é percebido além de seu fundador, e que ele não deixará de existir sem esse fundador (Adizes, 1993).

- Análise da segunda questão:

É importante dizer que o conceito moderno de ética tem origem etimológica a partir do grego ethos, usado em retórica a fim de evidenciar o caráter do orador, buscando inspirar, portanto, a confiança do público (Baumlin \& Baumlin, 1994). Seu sentido atual relaciona-se com hábito ou costume enquanto conjunto de máximas que regulam a vida individual na esfera coletiva (Marcondes, 2009). Já o termo moral é fruto da tradução do termo em grego para o latim mos, moris, resultando em moralis (Ricoeur, 1991).

Para Figueiredo e Guilhem (2008), resumidamente, é possível entender moral como um sistema de normas, princípios e valores, de caráter histórico e social, aceitos livre e conscientemente, ou seja, por convicção íntima, para regulamentar as inter-relações sociais. Ética representa o conhecimento teórico que visa conhecer, investigar e aclarar essas normas. Ou seja, "reserva-se à ética o estudo da moralidade do agir humano (bondade ou maldade dos atos humanos): Sua retidão frente à ordem moral" (Figueiredo \& Guilhem, 2008, p. 43).

Sabe-se ainda que diversos sistemas éticos têm sido construídos ao longo da história da humanidade com o intuito de delimitar as condutas dos sujeitos entre aquilo que é permitido e o que não é, mas o caminho de simplificar ou buscar modelar os comportamentos humanos, complexos por natureza, só resulta em um moralismo que sufoca e aprisiona. Neste sentido, o entendimento sobre ética deve estar atrelado à necessidade de criar regras para tratar os interesses múltiplos, a fim de evitar o triunfo, por exemplo, do horror como instrumento para a resolução de conflitos, ou mesmo a ideia de homogeneização.

Assim, o ethos precisa ser o espaço para o diálogo, para a reflexão, ou seja, para a prática da práxis. À ética cabe, portanto, a difícil tarefa de limitar e submeter à capacidade de ação os juízos, critérios, valores, sem os quais seria insuportável viver. Diante disso, é necessário, fundamentalmente, considerar o outro, tratar esse outro como gostaria de ser tratado, entretanto, no caso estudado foi possível identificar práticas que visavam interesses próprios, sendo prejudiciais aos interesses coletivos.

\section{- Análise da terceira questão:}

David (2004) diz que o empreendedor social participa como ator principal em ações relativas ao bem comum, interferindo diretamente em um grupo/organização através de suas propostas, provocando e inspirando mudanças nas relações sociais. Segundo Alvord, Brown e Letts (2004) ele mobiliza as ideias, competências e recursos - financeiros, humanos e políticos. Thompson (2002) diria que isso requer uma liderança forte e comprometimento. Muitos, inclusive, de acordo com esse autor, preferem ser chamados de "líderes comunitários", por associarem o termo "empreendedor" somente aos negócios e não verem o capital social como fruto do empreendedorismo.

No entanto, Dees (2001) já entendia que nem todo líder de organização social pode ser considerado empreendedor. Para ele, o empreendedor social é rara espécie de líder e deve ser reconhecido como tal. Perren 
(2000), por sua vez, também havia dito que a diferença está caracterizada pelo fato de que líderes atuam em diversas áreas da atividade humana - as forças armadas, as instituições religiosas, política e esporte, por exemplo - enquanto a atuação dos empreendedores tende a ser relacionada, prioritariamente, com a criação e a operação de uma organização (empresa, organismo público ou organização não governamental). (Error 1: La referencia: Dees (2001) está ligada a un elemento que ya no existe)

O referido autor fez uma comparativa baseada nos componentes conceituais de cada um dos construtos e considerou a importância atribuída pelas pesquisas aos fatores contextuais (variáveis sociais e econômicas relacionadas às atividades empreendedoras e de liderança). Esta análise mostrou que liderança e empreendedorismo compartilham três componentes conceituais: (1) Força pessoal, (2) inovação e visão e (3) aceitação de risco. Os componentes conceituais mais característicos do empreendedorismo são: Crença no controle sobre os eventos, tolerância à ambiguidade, necessidade de independência e identificação de oportunidades. A liderança, por sua vez, está mais associada à comunicação e habilidades sociais, confiabilidade, habilidade para motivar e orientação para equipe.

Ao buscar integrar as pesquisas realizadas na área do comportamento de liderança, Yukl, Gordon e Taber (2002) propõem uma taxonomia hierárquica que combina categorias, oferecendo uma proposta de estrutura para os comportamentos de liderança. São elas:

- Liderança Orientada para a Tarefa: Planeja atividades de curto prazo, explicita os objetivos das tarefas e as expectativas sobre cada um e monitora a operação;

- Liderança Orientada para o Relacionamento: Oferece suporte e encoraja, reconhece realizações e contribuições, desenvolve habilidades e confiança, consulta para decidir e dá empowerment para a solução de problemas;

- Liderança Orientada para a Mudança: Monitora o ambiente externo, propõe estratégias inovadoras ou novas visões e estimula o pensamento inovador;

Para Fischer (2006), o processo de liderança é composto por quatro etapas:

1. Início, momento em que o empreendimento começa a desenvolver-se com a presença do "pai" da ideia. Muitos valores organizacionais ainda estão sendo trabalhados para dar sustentabilidade à iniciativa e a cultura organizacional começa a ser criada;

2. Institucionalização, momento em que o empreendimento começa a cuidar de aspectos da estrutura organizacional e das estratégias;

3. Sucesso/descentralização, é o momento mais difícil, segundo a referida autora, pois o sucesso do empreendimento leva à necessidade de sua ampliação e descentralização; momento chave para compartilhar poder, quando costumam ocorrer conflitos relacionados a interesses e disputas de poder;

4. Redes sociais, momento de formação de "conglomerados", compartilhamento de cultura, e conhecimento tecnológico e gerencial.

As duas primeiras etapas, conforme Fischer (2006), caracterizam-se por uma liderança carismática, enquanto nas etapas seguintes costumam ocorrer processos políticos com maior participação democrática.

Todos estes estudos demonstraram a importância do líder-empreendedor durante a criação e no desenvolvimento de um empreendimento social, pois ainda que na origem de um empreendimento possa estar apenas um indivíduo, em um determinado momento, este irá mobilizar um grupo organizado. Com isso, segundo Bertero (1996), ele vai exercer um papel decisivo no delineamento da cultura desse empreendimento ao inserir nele seus valores e visão de mundo. Nesse sentido, é importante destacarmos a influência dos traços de personalidade dos empreendedores no processo de formação da cultura organizacional, como ainda a influência desta no próprio perfil do empreendedor social.

Schein (1986) trabalhou com um conjunto de pressupostos para descrever esta cultura. Assim, para esse autor a cultura organizacional é:

[...] um conjunto de pressupostos básicos que um grupo inventou, descobriu ou desenvolveu ao aprender como lidar com os problemas de adaptação externa e integração interna e que funcionaram bem o suficiente 
para serem considerados válidos e ensinados a novos membros como a forma correta de perceber, pensar e sentir, em relação a esses problemas. (Shein, 1986, p. 47).

Em complemento a esta definição, Fleury (1996) incorporou a dimensão política, concebendo a cultura organizacional como:

[...] um conjunto de valores e pressupostos básicos expresso em elementos simbólicos, que em sua capacidade de ordenar, atribuir significações, construir a identidade organizacional, tanto agem como elemento de comunicação e consenso, como ocultam e instrumentalizam as relações de dominação (Fleury, 1996, p. 22).

Morgan (1996) ofereceu-nos uma visão mais ampla, ao perceber a organização como um fenômeno cultural que varia de acordo com o estágio de desenvolvimento da sociedade, além de que ela varia de uma sociedade para outra. Para ele, "[...] a cultura refere-se ao padrão de desenvolvimento refletido nos sistemas sociais de conhecimento, ideologia, valores, leis e rituais cotidianos” (Morgan, 1996, p. 116).

Com base nestas colocações, podemos dizer que não só a cultura do empreendimento social sofre influências de seu fundador como a própria personalidade e o comportamento deste podem ser influenciados por uma cultura formada a partir da interação de todas as pessoas envolvidas no empreendimento.

Segundo Prioste (2004), esta cultura organizacional carrega um forte apelo emocional vivenciado pelo fundador e compartilhado com os membros envolvidos. A liderança é, portanto, delineada por valores culturais que estimulem as pessoas em direção aos objetivos compartilhados, os quais podem ser do grupo, da organização e do fundador e que criam um sentimento de coletividade que permeia o empreendimento e dá coerência às diferentes atividades.

Assim, para o caso apresentado sugere-se ao professor incitar as discussões a partir das colocações e explicações dos alunos, no intuito de fomentar um olhar mais abrangente, entendendo a importância do papel do líder na condução estratégica da organização. É possível dizer que João Alexandre planejava as atividades de curto prazo, sem uma preocupação em consultar para decidir e sem uma perspectiva de longo prazo. Já a nova presidente estava caminhando para uma liderança orientada para o relacionamento, que é importante para dar suporte a potenciais mudanças futuras de cenário, ou seja, é fundamental preparar a equipe para aproveitar oportunidades de maneira inovadora.

Por fim, cabe dizer que é fundamental que exista uma combinação entre estas perspectivas de liderança, mas sem, por exemplo, dar atenção ao relacionamento é difícil ater-se às mudanças, pois tal trabalho depende de uma cooperação em equipe.

- Análise da quarta questão:

Para Newell e Swan (2000), nos empreendimentos sociais tende-se a atribuir à confiança significados pautados na lealdade, em expectativas compartilhadas, nas relações baseadas na reciprocidade e na boa vontade entre todos. Deste modo, a união de todos pela busca de um planejamento para a organização é essencial para a continuidade da mesma. Essa união é entendida como o resultado da colaboração e a combinação de esforços de todos os envolvidos no empreendimento. Adachi (2006) sugere que este planejamento esteja fundamentado nos valores, na missão e na visão de futuro do empreendimento, assegurando a consolidação de padrões culturais que sejam importantes para a perenidade da organização.

Caso não haja esse envolvimento do grupo (associados) no planejamento da organização, corre-se o risco de haver a centralização de poderes na pessoa do fundador, que, segundo Adachi (2006), faz com que ele assuma um papel multifuncional, dificultando a delegação de responsabilidades. Desta maneira, a resistência por parte dos associados e funcionários às inovações e mudanças pode ocorrer em consequência da dependência em relação às diretrizes do fundador. Por isso, é necessário desenvolver a consciência de que todos também fazem parte do processo de construção das diretrizes do empreendimento, buscando assim minimizar esta resistência às mudanças. 
Além disso, o processo sucessório deve ser percebido não só como uma mudança, mas como um gerador de oportunidades de crescimento, aprendizado e desenvolvimento para as pessoas envolvidas e para o próprio empreendimento (Wolfred, 2002; Teegarden, 2004; Adams, 2004, 2006; Kunreuther \& Corvington, 2007).

Cohn (1991) expõe que é necessário comprometimento tanto dos fundadores, como daqueles envolvidos com o empreendimento. Isso possibilitará um maior fluxo de comunicação, uma partilha e uma compreensão de valores, gerando ingredientes essenciais para o processo sucessório.

Além disso, o envolvimento do grupo (associados) no planejamento é importante por oferecer suporte para a gestão da mudança organizacional advinda do processo sucessório. Ao participar do processo de transição, pulverizando os interesses dos associados de uma geração para a outra, há uma preparação para esta nova relação.

\section{REFERÊNCIAS}

Adachi, P. P. (2006). Familia S. A.: gestão de empresa familiar e solução de conflitos. São Paulo: Atlas.

Adams, T. (2004). Capturing the Power of Leadership Change: Using Executive Transition Management to Strengthen Organizational Capacity (Vol. 1). Baltimore: Annie E. Casey Foundation.

Adams, T. (2006). Staying Engaged, Stepping Up: Succession planning and executive transition management for nonprofit boards of directors (Vol. 5). Baltimore: Annie E. Casey Foundation.

Adizes, I. (1993). Os ciclos de vida das organizaçôes: como e por que as empresas crescem e morrem e o que fazer a respeito (2a. ed.) São Paulo: Pioneira.

Alvord, S. H., Brown, L. D., LETTS, C. W. (2004). Social entrepreneurship and societal transformation: an exploratory study. Journal of Applied Behavioral Science, 40(3), 260-282.

Banavoglia A., Mackinnon A. (2011). Executive Transitions: grant makers and non-profit leadership change. Recuperado em 26 fevereiro, 2009 de http://www.grantcraft.org/?pageid=1286.

Baumlim, J. S., Baumlim, T. F. (1994). Ethos: new essays in rhetorical and critical theory. Dallas: Southern Methodist University Press.

Bertero, C. O. (1996). Cultura organizacional e Instrumentalização do Poder. In M. T. L. Fleury, \& R. M. Fischer (Eds.), Cultura e Poder nas organizaçôes (2a. ed.). São Paulo: Atlas.

Brinckerhoff, P. C. (2007). Generations: The Challenge of a Lifetime for Your Nonprofit. Saint Paul: Fieldstone Alliance.

Cohn, M. (1991). Passando a tocha: como conduzir e resolver os problemas de sucessão familiar. São Paulo: Makron Books.

David, D. E. H. (2004). Intraempreendedorismo Social:perspectivas para o desenvolvimento social nas organizaçôes. Tese de doutorado, Universidade Federal de Santa Catarina, Florianópolis, SC, Brasil.

Dees, J. G. (1998). The Meaning of Social Entrepreneurship . Recuperado em 21 agosto, 2008 de http://www.fuqua.d uke.edu/centers/case/documents/dees_SE.pdf.

Figueiredo, A. M., Guilhem, D. (2008). Ética e moral. INTERthesis, 5(1), 29-46.

Fischer, R. M. (2006). Organizational culture in social enterprise. In SEKN Effective Management of Social Enterprises: lessons from businesses and civil Society Organizations in Iberoamerica (pp. 75-106). Cambridge: Harvard University Press.

Fischer, R. M. (2006). Palestra sobre Responsabilidade Social. In Conferência Interamericana sobre responsabilidade social da empresa: um bom negócio para todos. Salvador, BA, Brasil, IV.

Fleury, M. T. L. (1996). O Desvendar a Cultura de uma Organização: uma discussão metodológica. In M. T. L. Fleury, \& R. M. Fischer. Cultura e Poder nas Organizaçôes (2a. ed.). São Paulo: Atlas.

Freitas, M. E. de. (2007a). Quem paga a conta do assédio moral no trabalho. RAE eletrônica, 6(1), 1-7.

Freitas, M. E. de. (2007b). A metáfora da guerra e a violência no mundo do trabalho. In A. de P. Carrieri, \& L. A. S. Saraiva (Eds.), Simbolismo Organizacional no Brasil (pp. 277-291). São Paulo: Atlas. 
Larissa Sousa Cecílio \{in memoriam\}, et al. De Gata Borralheira À Cinderela: mas nem tudo é Conto...

Gódoi-de-Sousa, E. (2010). O processo sucessório em associações produtivas no Brasil: estrutura, desafios e oportunidades. Tese de doutorado, Universidade de São Paulo, São Paulo, SP, Brasil.

Goler, R. I. (2003). Making the Most of the Internal Interim Directorship. Journal for Nonprofit Management , 7 , 56-66.

Gonçalves, B. R. F. (2002). A transmissão do poder através do processo sucessório em pequenas e médias empresas familiares brasileiras: O caso da indústria de milho Anchieta LTDA. Dissertação de mestrado, Universidade Federal de Santa Catarina, Florianópolis, SC, Brasil.

Hall, H. (2006). Planning Successful Successions: Preparing for a Leader's Departure Can Prevent Problems. Chronicle of Philanthropy, 18, 1-6.

Kunreuther, F. (2005). Up Next: Generation Change and the Leadership of Nonprofit Organizations. Baltimore: Annie E. Casey Foundation.

Kunreuther, F., Corvington, P. A. (2007).Next Shift:Beyond the Nonprofit Leadership Crisis (Vol. 2). Baltimore: Annie E. Casey Foundation.

Leal, E. A., Famá, R. (2007) Governança nas Organizações do Terceiro Setor: Um estudo de caso. Anais dos Seminários em Administração PPGA/FEA/USP, São Paulo, SP, Brasil, 10.

Liteman, M. (2003). Planning for Succession: A Toolkit for Board Members and Staff of Nonprofit Arts Organizations. Chicago: Illinois Arts Alliance Foundation.

Lumpkin, G,, Dess, G. (1996). Clarifying the entrepreneurial orientation construct and linking it to performance. Academy of Management Review, 21(1), 135-172.

Marcondes, D. (2009). Textos básicos de ética: de Platão a Foucault. Rio de Janeiro: Jorge Zahar.

Matias-Pereira, J. A. (2010). Governança Corporativa Aplicada no Setor Público Brasileiro. Administração Pública e Gestão Social, 2(1), 110-135.

Melo Neto F. P., Froes C. (2002). Empreendedorismo social : a transição para a sociedade sustentável. Rio de Janeiro: Qualitymark.

Morgan, G. (1996). Imagens da Organização. São Paulo: Atlas.

Newell, S., Swan, J. (2000). Trust and inter-organizational networking. Human Relations, 53(10), 1287-1328.

Nobles, M. E. (2006). Executive Turnover Continues at Charities Large and Small. NonProfit Times, 20, 1-6.

Perren, L. (2000), Comparing entrepreneurship and leadership: A textual analysis, Report from the SME working group, London: CEML.

Prioste, C. D. (2004). Liderança Estratégica e Gestão de Conflitos no Terceiro Setor. Recuperado em 10 janeiro, 2009 de http://eduardobarbosa.com/sitedata/filesdt/textos_tecnicos/8/lideranca.pdf.

Ricoeur, P. (1991). O si-mesmo como um outro. Campinas: Papirus.

Schein, E. (1986). Organizational culture and leadership. San Francisco: Jossey Bass Publishers.

Teegarden, P. H. (2004). Nonprofit Executive Leadership and Transitions Survey. Recuperado em 20 abril, 2010 de ht tp://www.aecf.org/m/resourcedoc/aecf-NonProfitExecutiveLeadershipSurvey-2004.pdf.

Thompson, J. L. (2002). The world of the social entrepreneur. International Journal of Public Sector Management, $15(5), 412-431$.

Velloso, S. P. (2012). Governança corporativa e empresas familiares em processo sucessório: a visão de consultores e de familias empresárias. Dissertação de mestrado, Universidade Federal do Rio Grande do Sul, Porto Alegre, RS, Brasil.

Williams, K. (2005). Mentoring the Next Generation of Nonprofit Leaders: a Practical Guide for Managers. Recuperado em 10 março, 2010 de http://files.eric.ed.gov/fulltext/ED536786.pdf.

Wolfred, T. (2002). Stepping Up: A Board's Challenge in Leadership Transition. Recuperado em 15 novembro, 2009 de https://nonprofitquarterly.org/2002/12/21/stepping-up-a-boards-challenge-in-leadership-transition/.

Yukl, G., Gordon, A., Taber, T. (2002). A Hierarchical Taxonomy of Leadership Behavior: Integrating a HalfCentury of Behavior Research. Journal of Leadership e Organizational Studies, 9(1), 15-32. 
Administração Pública e Gestão Social, 2020, 12(2), AbriL-Julio, ISSN: 2175-5787

CC BY-NC-ND 